E3S Web of Conferences 1, 01002 (2013)

DOI: $10.1051 / \mathrm{e} 3$ sconf/20130101002

(C) Owned by the authors, published by EDP Sciences, 2013

\title{
Evaluation of Integrated Time-Temperature Effect in Pyrolysis Process of Historically Contaminated Soils with Cadmium (Cd) and Lead $(\mathrm{Pb})$
}

\author{
C. Bulmău ${ }^{1}$, D. M. Cocârță² ${ }^{2}$ A. M. Reșetar-Deac ${ }^{3}$ \\ ${ }^{1}$ Department of Energy Production and Use, University POLITEHNICA of Bucharest, Bucharest, Romania, email: \\ cora4cora@gmail.com \\ ${ }^{2}$ Department of Energy Production and Use, University POLITEHNICA of Bucharest, Bucharest, Romania, email: \\ dianacocarta13@yahoo.com \\ ${ }^{3}$ National Research and Development Institute for Environmental Protection, Bucharest, Romania, ana6209@yahoo.com
}

\begin{abstract}
It is already known that heavy metals pollution causes important concern to human and ecosystem health. Heavy metals in soils at the European level represents $37.3 \%$ between main contaminates affecting soils (EEA, 2007). This paper illustrates results obtained in the framework of laboratory experiments concerning the evaluation of integrated time-temperature effect in pyrolysis process applied to contaminated soil by two different ways: it is about heavy metals historically contaminated soil from one of the most polluted areas within Romania, and artificially contaminated with PCB-containing transformer oil. In particular, the authors focused on a recent evaluation of pyrolysis efficiency on removing lead $(\mathrm{Pb})$ and cadmium $(\mathrm{Cd})$ from the contaminated soil. The experimental study evaluated two important parameters related to the studied remediation methodology: thermal process temperature and the retention time in reactor of the contaminated soils. The remediation treatments were performed in a rotary kiln reactor, taking into account three process temperatures $\left(400^{\circ} \mathrm{C}, 600^{\circ} \mathrm{C}\right.$ and $\left.800^{\circ} \mathrm{C}\right)$ and two retention times: $30 \mathrm{~min}$. and $60 \mathrm{~min}$. Completed analyses have focused on pyrolysis solids and gas products. Consequently, both ash and gas obtained after pyrolysis process were subjected to chemical analyses.
\end{abstract}

Key words: Cadmium $(\mathrm{Cd})$, Lead $(\mathrm{Pb})$, pyrolysis, efficiency, process temperature, retention time

\section{Introduction}

Soil contamination with heavy metals represents one of the most important environmental issues around the world. Concerning this topic, it is important to use appropriate selection criteria for choosing suitable remediation option. As it was already recognized, removing heavy metals from polluted soils is a difficult mission (Wuana and Okieimen, 2011).

If various metals are nutritionally fundamental elements at low levels (e.g., copper [Cu], selenium [Se], and zinc $[\mathrm{Zn}]$ ), once that concentration level is increasing, these are becoming toxics. On the other hand, there are different compounds that have no known biological functions (e.g., lead [Pb], arsenic [As], and mercury [Hg]) (Fairbrother et al., 2007). In fact, heavy metals as $\mathrm{Pb}$, cadmium [Cd], As and $\mathrm{Hg}$ are highly toxic, affecting cognitive, neurological and reproductive functions, being associated with negative effects in many organs and tissues, including kidneys, brain, bones, and the cardiovascular and respiratory systems. They are also highly bio-accumulative, and health effects may occur after long-term low-level exposure (UNDP, 2011).

In the last years, for the remediation of the polluted sites, thermal decontamination technologies present an important scientific and practical interest because they can provide high efficiency in removing especially organic pollutants. Thermal treatments are considered the most popular and versatile techniques because they can be applied to many species of organic contaminants (Merino and Bucalá, 2007). One of the methods used for the remediation of heavy metals contaminated soils is thermal treatment.

These days, pyrolysis, thermal treatment conducted in the absence of oxygen, is becoming popular in the direction of solid wastes treatment (Kistler et al., 1987). Comparing to incineration, pyrolysis technologies present many advantages: decreasing of the flue gas amount that must be cleaned; production of acidic gases and dioxins is repressed under reducing conditions, and the release of heavy metals concentrated in the pyrolysis residue is well suppressed, especially chromium (Erdem and Ożverdi, 2008). 
The experimental study presented in the present paper is a part of an extensive research developed in the framework of RECOLAND project co-financed under the Sectorial Operational Programme "Increase of Economic Competitiveness" POSCCE-A2-O2.1.2.-2009-2, RECOLAND (ID519, SMIS-CSNR: 11982 (2010-2013)). In the framework of the research carried out, decontamination methods for organic and inorganic polluted soils are studied. During the research project development methods as electrochemical remediation, bioremediation and thermal treatment: incineration and pyrolysis are studied, placing a particular attention not only on identifying efficiencies of the methods applied, but also on costs and especially on risk assessment. For present work authors focused on results on pyrolysis efficiency concerning $\mathrm{Cd}$ and $\mathrm{Pb}$ removal from artificially $\mathrm{PCBs}$ and heavy metals anthropogenic contaminated soil. The remediation treatments linked to the pyrolysis process were performed in a rotary kiln reactor, for three process temperatures $\left(400^{\circ} \mathrm{C}, 600^{\circ} \mathrm{C}\right.$ and $\left.800^{\circ} \mathrm{C}\right)$ and two retention times: $30 \mathrm{~min}$. and $60 \mathrm{~min}$.

\section{Materials and Methods}

\section{Sampling techniques.}

Soil from Central Romania was the subject to the present experimental study. It is about historically contaminated with heavy metals ( $\mathrm{Pb}, \mathrm{Cd}, \mathrm{Ni}, \mathrm{As}, \mathrm{Zn}, \mathrm{Cu}, \mathrm{Fe}, \mathrm{Mn}, \mathrm{Cr}, \mathrm{Co}$, $\mathrm{Hg}$, As and $\mathrm{Be}$ ) due to industrial activities that took place for about 70 years: a plant which produced carbon black for dies and tires from 1936 until 1993, and a non-ferrous metallurgical smelter which started to work in 1939. The polluted soil samples were collected from an area of 4000 $\mathrm{m}^{2}$ according to STAS 7184/1-75, SR ISO 11074-2:2001.

An important concern related to pyrolysis of contaminated soil was the $\mathrm{Cd}$ and $\mathrm{Pb}$ content in gas pyrolysis immediately after the reactor. With this aim, extraction and analysis was conducted in accordance with EN 13284-1. In order to determine the $\mathrm{Cd}$ and $\mathrm{Pb}$ concentration levels, samples were withdrawn isokinetically from the pyrolysis gas before the flue gas system, and in this way, particulate emissions were collected on a quartz fibre filter.

\section{Concentration levels of $\mathrm{Cd}$ and $\mathrm{Pb}$ in soil}

In order to identify removal efficiency, $\mathrm{Cd}$ and $\mathrm{Pb}$ concentration level in soil was first determined. Qualitative analyses were performed for identifying the amount of $\mathrm{Cd}$ and $\mathrm{Pb}$ content in contaminated soil samples. Because for the recovered samples from raw gas there is not a standard extraction method, mineralization was performed in the same way as the soil samples (ISO 11466/1999). Heavy metals concentration levels for the particular contaminants from both pyrolysis ashes and gas were determined by flame atomic absorption spectrometer (Shimadzu model AA 6300) according to SR ISO 11047/1999.

Results related to chemical analysis revealed high concentration levels for two investigated heavy metals as shown in table 1. According to national regulation, Order $756 / 1997$, the intervention thresholds for sensible use is established at $5 \mathrm{mg} / \mathrm{kg}_{\mathrm{dw}}$ for $\mathrm{Cd}$ and $100 \mathrm{mg} / \mathrm{kg}_{\mathrm{dw}}$ for $\mathrm{Pb}$. In this context, identified concentrations are 7.30 higher for $\mathrm{Cd}$, and 34.41 higher for $\mathrm{Pb}$. This reference concentration levels were decided because the site selected for this study is an agricultural field.

In this type of plant, feeding is done manually, with a capacity between 10 to $60 \mathrm{~kg} / \mathrm{h}$ of solid fuel with different moisture and energy contents. Contaminated soil pyrolysis tests were conducted with different levels of process parameters included in Table 2 .

Table 1. Concentrations of $\mathrm{Cd}$ and $\mathrm{Pb}$ in raw soil

\begin{tabular}{|c|c|}
\hline Metal specie & $\begin{array}{c}\text { Concentration } \\
{\left[\mathbf{m g} / \mathbf{k g}_{\mathbf{d w}}\right]}\end{array}$ \\
\hline $\mathrm{Cd}$ & 37 \\
\hline $\mathrm{Pb}$ & 3441 \\
\hline
\end{tabular}

Pyrolysis experimental facility

Experimental tests were performed using a semi-industrial scale pilot plant.

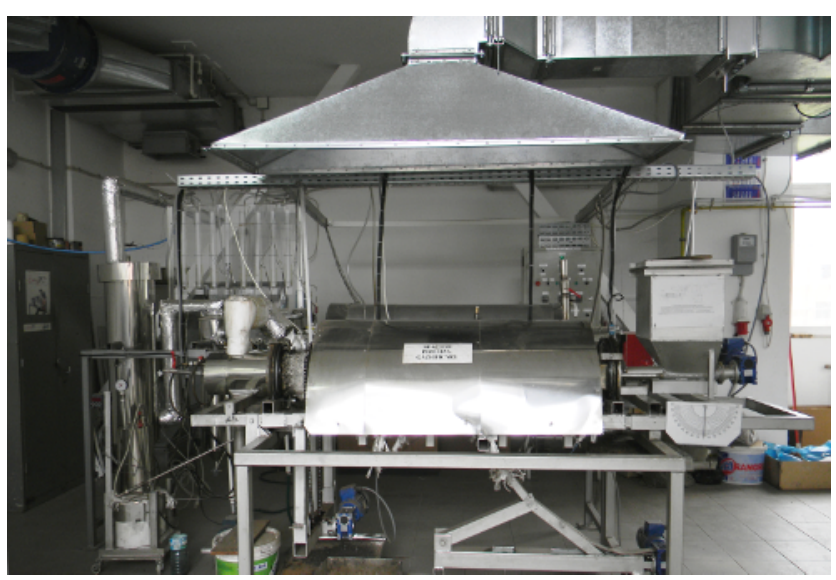

Fig. 1. Semi-industrial scale pyro-combustion pilot plant

Table 2. Pyrolysis operating conditions

\begin{tabular}{|l|c||c|}
\hline Process parameter & Value & Unit \\
\hline \multirow{3}{*}{ Temperature } & 400 & \multirow{2}{*}{${ }^{\circ} \mathrm{C}$} \\
\cline { 2 - 2 } & 600 & \\
\cline { 2 - 2 } & 800 & \multirow{2}{*}{$\mathrm{min}}$. \\
\hline \multirow{2}{*}{ Retention time } & 30 & $\mathrm{~g}$ \\
\hline Mass flow rate & 60 & $1 / \mathrm{min}$ \\
\hline Nitrogen flow & 600 & \\
\hline
\end{tabular}

\section{Results and Discussion}

Even that pyrolysis is commonly used for removal of organic compounds from soils, volatile metals may be removed as a result of the higher temperatures associated 
with the process, but are in the same way not destroyed. Results from experimental tests illustrate interesting behaviour of $\mathrm{Cd}$ and $\mathrm{Pb}$ concentration levels according to pyrolysis operating conditions. Fig. 2 illustrates time-temperature effect on $\mathrm{Cd}$ concentration trend. As it can be noticed, no matter what retention time value was considered (30 min. or $60 \mathrm{~min}$.), concentrations have the same trend. Differences are with regard to removal efficiencies as a consequence of pyrolysis process temperatures. If in case of $400^{\circ} \mathrm{C}$ and $600^{\circ} \mathrm{C}$ pyrolysis process temperature $\mathrm{Cd}$ concentration is increasing, a process temperature of $800^{\circ} \mathrm{C}$ is ensuring important efficiencies for $\mathrm{Cd}$ removal from soil in both $30 \mathrm{~min}$. and 60 min retention times: $78 \%$ and $86 \%$, respectively. So, experiments have demonstrated that $\mathrm{Cd}$ was non-volatile for pyrolysis at $400^{\circ} \mathrm{C}$ and $600^{\circ} \mathrm{C}$, even if it was considerable evaporated at $800^{\circ} \mathrm{C}$, due to the high volatility of cadmium species formed during high temperature processes. Additionally, it was shown that, increasing retention time from $30 \mathrm{~min}$. to $60 \mathrm{~min}$., for the same pyrolysis temperature of $800^{\circ} \mathrm{C}, \mathrm{Cd}$ concentration in pyrolysis ash is almost half (Fig. 2). Figure 3 illustrates $\mathrm{Pb}$ concentration comportment concerning ashes produced by pyrolysis thermal treatment.

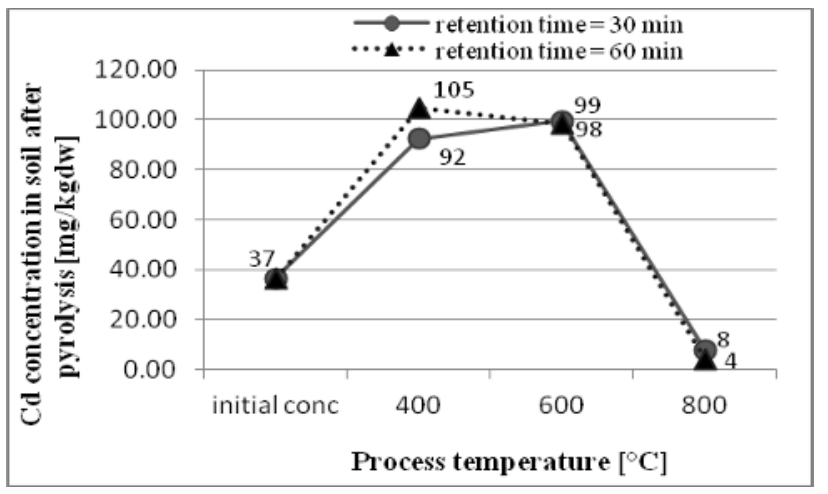

Fig. 2. Cd concentrations in pyrolysis ashes after contaminated soil thermal treatment

If in case of $\mathrm{Cd}$ behaviour when higher retention time was ensured, higher efficiency was obtained, in case of $\mathrm{Pb}$ contaminant, for the same process temperature $\left(800^{\circ} \mathrm{C}\right), \mathrm{Pb}$ concentration level is increasing with about $5 \%$ for $30 \mathrm{~min}$., while decreasing with about $14 \%$ for $60 \mathrm{~min}$. retention time (Fig. 3).

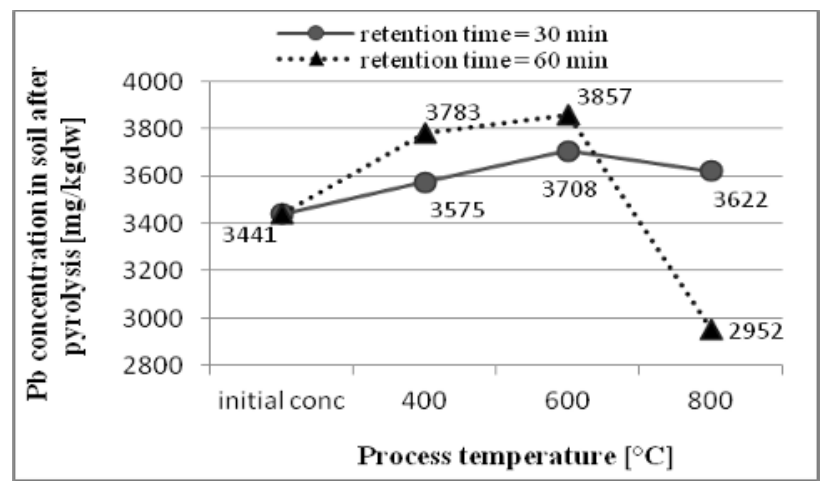

Fig. 3. $\mathrm{Pb}$ concentrations in pyrolysis ashes after contaminated soil thermal treatment
As volatile metals may be removed as a result of the higher temperatures associated with the process, but they are not destroyed, also metals from the particulate emissions collected on a quartz fibre filter were analysed. Fig. 4 and Fig. 5 evidence $\mathrm{Cd}$ and $\mathrm{Pb}$ concentration levels from pyrolysis gas as a consequence of time-temperature effect operating process.

In order to evaluate the main results gained during the laboratory experiments, important review of related literature from research papers was completed. Comparisons between our results and the literature data (Zhang et al., 2009; Wijesekara et al., 2007) confirmed obtained data concerning the pyrolysis process removing efficiencies and heavy metals behaviour. A good example in this respect is offered in Fig. 6.

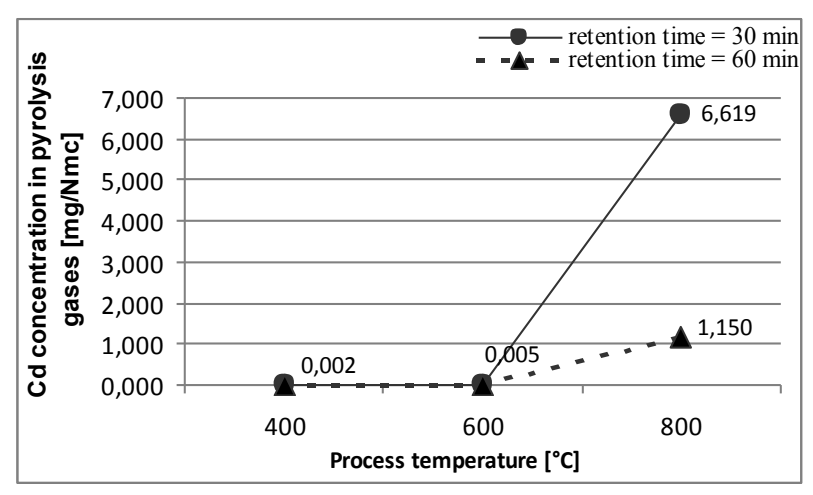

Fig. 4. Cd concentrations in raw gas after contaminated soil thermal treatment

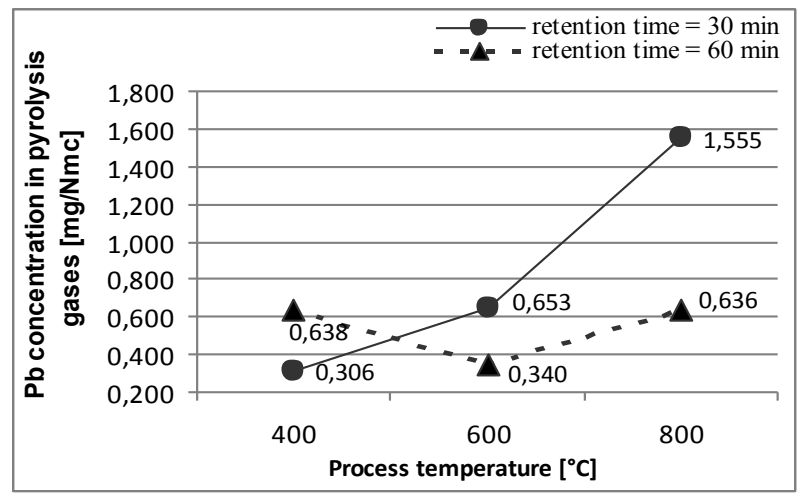

Fig. 5. $\mathrm{Pb}$ concentrations in raw gas after contaminated soil thermal treatment

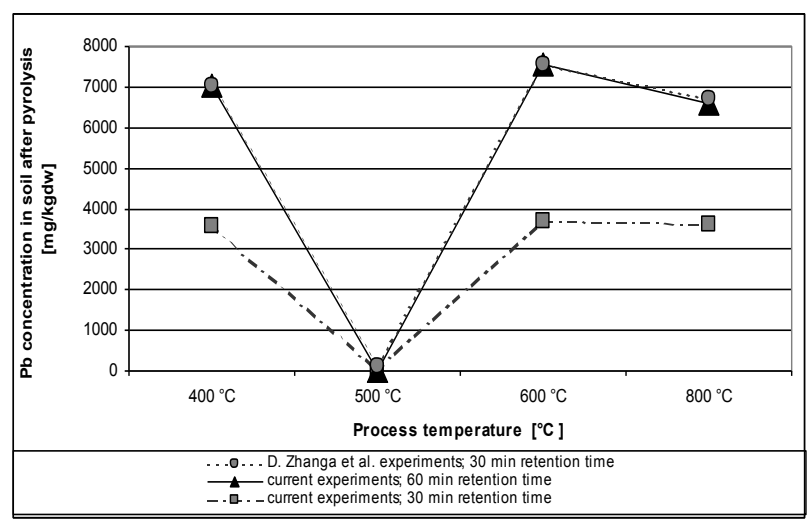

Fig. 6. $\mathrm{Pb}$ concentration behaviour during different pyrolysis experiments 


\section{Conclusion}

Evaluation of the integrated time-temperature effect on metals removal efficiency from soils and emissions $(\mathrm{Cd}$ and $\mathrm{Pb}$ content in pyrolysis gas before post-combustion chamber or flue gas cleaning system) were assessed. Concerning pyrolysis efficiency on $\mathrm{Cd}$ and $\mathrm{Pb}$ removal from contaminated soil demonstrated a significant dependence of concentration by the thermal process temperature. For both metals $(\mathrm{Cd}$ and $\mathrm{Pb}), 400^{\circ} \mathrm{C}$ and $600^{\circ} \mathrm{C}$ pyrolysis process temperature increased concentration levels in ashes as already demonstrated in previously related research (Zhang et al., 2009; Wijesekara et al., 2007). Only $800^{\circ} \mathrm{C}$ pyrolysis process temperature for $60 \mathrm{~min}$. retention time, ensured for both heavy metals removing efficiency from contaminated soil: $86 \%$ for $\mathrm{Cd}$ and $14 \%$ for $\mathrm{Pb}$. At different retention times, at $800^{\circ} \mathrm{C}$, just $\mathrm{Cd}$ has comparable removing efficiencies, while $\mathrm{Pb}$ is removed just after $60 \mathrm{~min}$. Accordingly, it can be noticed that $\mathrm{Cd}$ can be efficiently remediated by pyrolysis treatment conducted at high temperature process. Cadmium was non-volatile during pyrolysis at $400^{\circ} \mathrm{C}$ and $600^{\circ} \mathrm{C}$, while it was partially evaporated at $800^{\circ} \mathrm{C}$. The high evaporation of $\mathrm{Cd}$ for high process temperature requires a convenient flue gas cleaning system to recover the contaminant from the gas pyrolysis (Fig. 4).

As already mentioned, $\mathrm{Pb}$ contaminated soil removal efficiency of $14 \%$ was gained only at $800^{\circ} \mathrm{C}$, similar as in previously related research where an efficiency of $15 \%$ was identified (Wijesekara et al., 2007). With this concern, it is important to evaluate the stability of the remaining $\mathrm{Pb}$ in the pyrolysis ashes as a consequence of the reduced volatilisation of the metal (Fig. 6). Additionally, leaching behaviour of metals is one of the key ways to describing the stability of metals during thermal treatment (Wijesekara et al., 2007).

These experimental works showed that, from the point of view of the environmental impact, not only removal efficiency is an significant aspect, but also emissions assessment from pyrolysis of contaminated soil with $\mathrm{Cd}$ and $\mathrm{Pb}$ is an important stage; this is because $\mathrm{Cd}$ and $\mathrm{Pb}$ behaviour is governed by the pyrolysis time-temperature effect.

\section{Acknowledgements}

This work was supported under the Sectorial Operational Programme "Increase of Economic Competitiveness" POSCCE-A2-O2.1.2.-2009-2, RECOLAND ID519, SMIS-CSNR: 11982, Nb. 182/18.06.2010 (2010-2013) and the Sectorial Operational Programme Human Resources Development 2007-2013 of the Romanian Ministry of Labour, Family and Social Protection through the Financial Agreement POSDRU/89/1.5/S/62557.

\section{References}

EEA (European Environmental Agency), Progress in management of contaminated sites. Report CSI 015, Copenhagen, Denmark: European Environment Agency 2007.

EN 13284-1:2002, Stationary source emissions. Determination of low range mass concentration of dust. Manual gravimetric method.

Erdem M., Ożverdi A., Leaching behavior of chromium in chrome shaving generated in tanning process and its stabilization, J. of Hazardous Materials 2008; 156(1-3): 51-55.

Fairbrother A., Wenstel R., Sappington K., Wood W., Framework for Metals Risk Assessment, Frontier article, Ecotoxicology and Environmental Safety 2007; 68:145-227.

Kirk,W., Chris, C.Y.C., and Hilary, M.. Chromium behaviour during thermal treatment of MSW, J. of Hazardous Materials 2002; 90(1):39-49.

Merino J., Bucalá V., Effect of temperature on the release of hexadecane from soil by thermal treatment, J. of Hazardous Materials 2007; 143: 455-461.

UNDP, Chemicals and Gender, Environment and Energy Group, United Nations Development Program, Energy \& Environment Practice, Gender Mainstreaming Guidance Series, Chemicals Management 2011.

Zhang D., Kong H., Wu D., He S., Hu Z., Dai L., Impact of Pyrolysis Treatment on Heavy Metals in Sediment, Soil and Sediment Contamination 2009; 18:754-765,.

Wijesekara S., Navarro R., Hu Z., Matsumura M., Simultaneous Treatment of Dioxins and Heavy Metals in Tagonoura Harbor Sediment by Two-Step Pyrolysis, Soil and Sediment Contamination 2007; 16:569-584. 